\title{
Perfil fermentativo, composição bromatológica e perdas em silagem de bagaço de laranja com diferentes inoculantes microbianos
}

\section{Fermentation profile, chemical composition and dry matter losses of orange pulp silage with different microbial inoculants}

\author{
Fabíola Cristine de Almeida Rego ${ }^{1 *}$; Agostinho Ludovico²; Luiz Cesar da Silva²; \\ Lisiane Dornelles de Lima'; Elsa Walter Santana ${ }^{1}$; Mônica Chaves Françozo ${ }^{3}$
}

\begin{abstract}
Resumo
Objetivou-se com este experimento avaliar os efeitos de inoculantes microbianos sobre as perdas por gases e efluentes, recuperação de matéria seca, $\mathrm{pH}$, ácidos graxos voláteis e composição bromatológica de silagens de bagaço de laranja, usando-se um delineamento inteiramente casualizado, com quatro tratamentos e quatro repetições. Os tratamentos foram: silagem de bagaço de laranja (CONT), silagem de bagaço de laranja + Lactobacillus plantarum (LAC), silagem de bagaço de laranja + Lactobacillus buchneri (BUCH); silagem de bagaço de laranja + Lactobacillus plantarum e buchneri (LACBUCH). Os inoculantes foram aplicados na razão de 25 litros de solução por tonelada de forragem, contendo $1 \times 10^{3}$ UFC respectivamente de Lactobacillus plantarum e de Lactobacillus buchneri por grama de silagem. Não houve efeito do uso de diferentes inoculantes sobre as perdas por gases e efluentes, assim como no $\mathrm{pH}$. Os teores de matéria seca, proteína bruta, carboidratos não fibrosos, matéria mineral, extrato etéreo e o perfil de ácidos graxos não sofreram alterações significativas com a inclusão dos inoculantes. Os teores de fibra em detergente neutro e fibra em detergente ácido foram superiores para a silagem com Lactobacillus buchneri em relação à silagem controle. O uso de inoculantes microbianos na silagem de bagaço de laranja não resulta em benefícios relacionados às perdas durante a ensilagem ou componentes nutricionais.
\end{abstract}

Palavras-chave: Efluentes, gases, Lactobacillus buchneri, Lactobacillus plantarum, perfil de ácidos graxos

\begin{abstract}
The objective of this experiment was to evaluate the effects of microbial inoculants on the reduced concentration of gases and effluent, dry matter recovery, $\mathrm{pH}$, volatile fatty acids, and chemical composition of orange pulp silage, using a completely randomized design, with four treatments and four replicates per treatment. The treatments were: orange pulp silage (CONT), citrus pulp silage + Lactobacillus plantarum (LAC), citrus pulp silage + Lactobacillus buchneri (BUCH), citrus pulp silage + Lactobacillus plantarum and buchneri (LACBUCH). Inoculants were applied at a rate of 25 liters of solution per ton of citrus pulp containing $1 \times 10^{3}$ CFU respectively of Lactobacillus plantarum and Lactobacillus buchneri per gram of silage. There was no effect of the usage of different inoculants
\end{abstract}

\footnotetext{
${ }^{1}$ Profs. do Programa de Mestrado em Saúde e Produção de Ruminantes, Universidade Norte do Paraná, UNOPAR, PR 218 - KM 01 - Jd. Universitário, CEP 86702-670 - Cx. P. 560, Arapongas, PR. E-mail: fabíola_rego@yahoo.com.br; isidelima@gmail. com; elsahws@hotmail.com

${ }^{2}$ Profs. do curso de Medicina Veterinária, UNOPAR, Arapongas, PR. E-mail: agostinho@rocketmail.com; silvaluizcesar@gmail. com

${ }^{3}$ Discente de Mestrado do Programa de Mestrado em Saúde e Produção de Ruminantes, UNOPAR, Arapongas, PR. E-mail: monicacf.vet@hotmail.com

* Autor para correspondência
} 
on the reduction of gas and effluent, as well as the $\mathrm{pH}$ of the silage. The dry matter (DM), crude protein (CP), non-fibrous carbohydrate (NFC), mineral matter (MM), ether extract (EE) and the profile of fatty acids did not change significantly with the inclusion of the inoculants. The contents of neutral detergent fiber (NDF) and acid detergent fiber (ADF) were higher for silage with Lactobacillus buchneri compared to control. The administration of microbial inoculants in orange pulp silage did not result in benefits relative to the dry matter losses during ensiling or the nutritional components.

Key words: Effluent, gas, Lactobacillus buchneri, Lactobacillus plantarum, profile fatty acids

\section{Introdução}

O bagaço de laranja é um coderivado oriundo da indústria de suco de laranja, que representa 50\% do total da fruta e pode ser utilizado como alimento volumoso para animais ruminantes, uma vez que apresenta valor nutricional semelhante a outros volumosos. Este coderivado apresenta na forma in natura $24,9 \%$ MS, $8,03 \%$ de PB e $79,0 \%$ de NDT, segundo Macedo et al. (2007). Além do elevado teor de umidade apresentado, o bagaço de laranja é um material higroscópico, absorvendo umidade do ar, dificultando assim o armazenamento do produto. O ideal é armazená-la sobre estrados, ensacada, com monitoramento constante da temperatura (MENEGHETTI, DOMINGUES; 2008).

Considerando este entrave, uma das alternativas para o uso do bagaço de laranja úmido é a conservação na forma de silagem (ÍTAVO et al., 2000a, b), o que agrega valor nutricional e o conserva por mais tempo, tornando-o mais interessante no uso em criações. As características da silagem de bagaço de laranja já foram estudadas, entretanto apresentam muitas divergências com relação à composição bromatológica e perfil fermentativo, encontradas na literatura (MEGÍAS; MARTINEZTERUEL; GALLEGO, 1993; ÍTAVO et al., 2000a), provavelmente devido às diferenças existentes entre os processos utilizados nas indústrias esmagadoras de citrus; o que ressalta a importância deste estudo, principalmente em regiões em que a polpa tem relevância econômica.

$\mathrm{Na}$ ensilagem do bagaço de laranja é indicado o uso de aditivos que auxiliem durante a fermentação, devido ao elevado teor de umidade contida na mesma; como por exemplo, o uso de farelos de grãos, que possuem baixo teor de umidade. Além de farelos, o uso de inoculantes microbianos na confecção de silos tem mostrado efeitos benéficos em materiais com alta umidade, resultando em silagem com melhor qualidade e com menores perdas. Outro fator importante é que alguns aditivos possuem propriedades capazes de melhorar o meio anaeróbico no silo, contribuindo para a ensilagem de materiais que não são considerados "ideais" para esta atividade.

Existem no mercado vários tipos de inoculantes microbianos; que podem conter bactérias homoláticas, heteroláticas, ou a mistura de ambas. Inoculantes com base em bactérias homoláticas promovem aumento na produção de ácido lático $\mathrm{e}$ rápida redução do $\mathrm{pH}$ da massa ensilada (KUNG; STOKES; LIN, 2003). Já as bactérias heteroláticas metabolizam o ácido lático e a glicose presentes durante a fermentação para síntese de ácido propiônico e ácido acético, eficazes no controle de fungos e demais microrganismos deterioradores (OUDE ELFERERINK et al., 2001).

Este trabalho teve o objetivo de avaliar o efeito do inoculante microbiano heterolático (Lactobacillus buchneri) em combinação ou não com bactéria homolática (Lactobacillus plantarum) sobre o $\mathrm{pH}$, a composição bromatológica, as perdas associadas à fermentação e perfil de ácidos orgânicos, em silagens de bagaço de laranja.

\section{Material e Métodos}

O bagaço de laranja in natura foi fornecida pela Corol Cooperativa Agroindustrial Citrus, pertencente à COCAMAR CITRUS, situada 
na cidade de Rolândia, PR. O delineamento experimental utilizado foi o inteiramente casualizado, com quatro tratamentos, sendo silagem de bagaço de laranja (CONT), silagem de bagaço de laranja + Lactobacillus plantarum (LAC), silagem de bagaço de laranja + Lactobacillus buchneri (BUCH); silagem de bagaço de laranja + Lactobacillus plantarum e Lactobacillus buchneri (LACBUCH). Foram realizadas 4 repetições por tratamento, totalizando 16 mini silos.

Os mini silos experimentais foram confeccionados, utilizando-se baldes plásticos de 12 litros. No fundo de cada balde foi colocado aproximadamente $1 \mathrm{~kg}$ de areia, separados da forragem por um tecido de algodão e uma tela, de maneira que possibilitou quantificar os efluentes. Procedeu-se então a compactação do bagaço de laranja nos baldes atingindo a densidade média de 654 $\mathrm{kg} / \mathrm{m}^{3}( \pm 35)$. Para tanto foram colocados entre sete e oito $\mathrm{kg}$ de bagaço de laranja por balde, compactadas em camadas sucessivas de $10 \mathrm{~cm}$ de espessura. Após a compactação do material ensilado os mini silos foram vedados com tampa plástica contendo uma "válvula de bunsen" adaptada, para permitir o escape dos gases oriundos da fermentação. Os mini silos foram pesados e armazenados durante 90 dias em local coberto e em temperatura ambiente.

Os inoculantes foram adicionados ao bagaço de laranja antes do enchimento dos baldes na forma de soluções aquosas utilizando-se pulverizadores manuais.Apósa aplicação amassa foi homogeneizada e compactada nos baldes. Os diferentes inoculantes foram aplicados na razão de 25 litros de solução por tonelada de forragem, de modo a conter $10^{3} \mathrm{UFC}$, respectivamente, de Lactobacillus plantarum e de Lactobacillus buchneri por grama de silagem.

As perdas com efluentes foram determinadas através da diferença de peso do mini silo vazio, com areia, tecido e tela plástica antes do enchimento e após a sua abertura, conforme Jobim et al. (2007). As perdas ocorridas durante a ensilagem foram determinadas considerando o peso e a concentração das diferentes frações bromatológicas no material no enchimento e após a abertura dos silos, conforme Jobim et al. (2007).

$\mathrm{O} \mathrm{pH}$ da silagem foi determinado utilizando a metodologia descrita por Kung Junior (1996). Foi colhido $50 \mathrm{~g}$ de amostra das silagens imediatamente após a abertura dos silos, adicionou-se $450 \mathrm{~mL}$ de água deionizada a cada amostra e triturou-se em liquidificador durante um minuto, então aferiu-se o $\mathrm{pH}$ utilizando-se um potenciômetro. $\mathrm{O} \mathrm{N}$-amoniacal (\% N-NH3 do $\mathrm{N}$ total) foi determinado segundo metodologia adaptada por Cândido et al. (2002).

Para a determinação dos ácidos orgânicos extraiu-se suco da silagem através de prensagem manual do material. Parte deste foi fixado e congelado para posterior determinação dos ácidos orgânicos (acético, propiônico, butírico, isobutírico, valérico e isovalérico), por meio de cromatografia gasosa (ERWIN; MARCO; EMERY, 1961).

Para avaliar a composição bromatológica das silagens, foram colhidas amostras do material in natura, antes da ensilagem (Tabela 1), e após a abertura dos mini silos. As amostras foram pré secadas em estufa a $55^{\circ} \mathrm{C}$ durante 48 horas, e, logo após trituradas em moinho tipo Willey dotado com peneira com crivos de um $\mathrm{mm}$ de diâmetro. Em seguida determinou-se os teores de matéria seca (MS), proteína bruta (PB), fibra em detergente neutro (FDN), fibra em detergente ácido (FDA), matéria mineral (MM) nitrogênio insolúvel em detergente neutro (NIDN), nitrogênio insolúvel em detergente ácido (NIDA), segundo metodologias descritas por Silva e Queiroz (2006). 
Tabela 1. Composição bromatológica do bagaço de laranja antes da ensilagem e após a abertura dos silos.

\begin{tabular}{|c|c|c|c|c|c|c|c|c|c|}
\hline \multirow{3}{*}{ Nutrientes } & \multirow{3}{*}{$\begin{array}{c}\begin{array}{c}\text { Antes } \\
\text { Ensilagem }\end{array} \\
\begin{array}{c}\text { Bagaço } \\
\text { de laranja }\end{array}\end{array}$} & \multicolumn{4}{|c|}{$\begin{array}{l}\text { Pós ensilagem } \\
\text { Tratamentos }^{1}\end{array}$} & \multirow{3}{*}{ Média } & \multirow{3}{*}{$\mathrm{CV}^{2}$} & \multirow{2}{*}{\multicolumn{2}{|c|}{$\mathrm{P}^{3}$}} \\
\hline & & \multirow[t]{2}{*}{ CONT } & \multirow[t]{2}{*}{ BUCH } & \multirow[t]{2}{*}{ LAC } & \multirow[t]{2}{*}{ LACBUCH } & & & & \\
\hline & & & & & & & & $\mathrm{C}$ & $\mathrm{T}$ \\
\hline MS & 18,73 & $18,92 \mathrm{a}$ & $18,56 \mathrm{a}$ & $21,06 \mathrm{a}$ & $18,69 \mathrm{a}$ & 19,31 & 2,86 & $* * *$ & NS \\
\hline PB & 7,06 & $7,01 \mathrm{a}$ & $7,12 \mathrm{a}$ & $7,21 \mathrm{a}$ & $7,24 \mathrm{a}$ & 7,14 & 3,26 & NS & NS \\
\hline FDN & 28,12 & $28,18 \mathrm{~b}$ & $29,31 \mathrm{a}$ & $28,32 \mathrm{ab}$ & $28,57 \mathrm{ab}$ & 28,59 & 1,71 & NS & $*$ \\
\hline FDA & 20,39 & $23,81 \mathrm{~b}$ & 24,49 a & $23,79 \mathrm{~b}$ & $23,30 \mathrm{~b}$ & 23,85 & 1,17 & $* * *$ & $* * *$ \\
\hline NIDN & 2,68 & $7,22 \mathrm{a}$ & $6,72 \mathrm{ab}$ & $5,97 \mathrm{~b}$ & $6,53 \mathrm{ab}$ & 6,61 & 6,67 & $* * *$ & $* *$ \\
\hline NIDA & 11,12 & $3,52 \mathrm{a}$ & 3,46 a & $3,40 \mathrm{ab}$ & $3,07 \mathrm{~b}$ & 3,36 & 4,90 & $* * *$ & $* *$ \\
\hline $\mathrm{CNF}^{4}$ & 65,49 & $61,93 \mathrm{a}$ & $60,03 \mathrm{a}$ & $61,03 \mathrm{a}$ & $60,92 \mathrm{a}$ & 61,13 & 1,33 & $* * *$ & NS \\
\hline MM & 7,15 & $9,13 \mathrm{a}$ & $9,66 \mathrm{a}$ & $9,62 \mathrm{a}$ & $9,73 \mathrm{a}$ & 9,53 & 5,04 & $* * *$ & NS \\
\hline $\mathrm{EE}$ & 3,81 & $3,37 \mathrm{a}$ & $3,51 \mathrm{a}$ & $3,76 \mathrm{a}$ & $3,67 \mathrm{a}$ & 3,58 & 7,37 & NS & NS \\
\hline
\end{tabular}

${ }^{1}$ CONT- silagem de bagaço de laranja, LAC - silagem de bagaço de laranja + Lactobacillus plantarum, BUCH - silagem de bagaço de laranja + Lactobacillus buchneri; LACBUCH - silagem de bagaço de laranja + Lactobacillus plantarum e buchneri

${ }^{2} \mathrm{CV}=$ coeficiente de variação;

${ }^{3}$ Probabilidade do erro tipo I pela análise de contrastes $(C)$ entre composição química do material antes e após ensilagem, e $\mathrm{T}$ o valor da probabilidade da diferença estatística entre as médias dos tratamentos pelo teste de Tukey, onde $* * *=\mathrm{P}<0,001$; $* *=\mathrm{P}<0,01 ; *=\mathrm{P}<0,05 ; \mathrm{NS}=$ não significativo;

${ }^{4} \mathrm{CNF}=100 \%-(\mathrm{PB} \%+\mathrm{FDN} \%-\mathrm{FDNPB}+\mathrm{EE} \%+$ Cinzas\% $)(\mathrm{HALL}, 2001) ;$

*Médias seguidas de letras iguais nas linhas não diferem pelo teste Tukey $(\mathrm{P}>0,05)$.

Fonte: Elaboração dos autores.

Para a determinação dos carboidratos nãofibrosos (CNF) empregou-se a fórmula descrita por Hall (2001), em que CNF $=100 \%-(\mathrm{PB} \%+$ FDN\% - FDNPB + EE\% + Cinzas\%) e FDNPB é a proteína bruta insolúvel em detergente neutro. Os carboidratos totais (CT) foram obtidos pela equação (SNIFFEN et al., 1992): CT $=100-(\% \mathrm{~PB}+\% \mathrm{EE}+$ \%cinzas).

Os dados foram submetidos às análises estatísticas descritivas, e a hipótese de normalidade foi testada pelo teste Shapiro-Wilk a 5\%. A variável "perdas por gases" não apresentou distribuição normal, portanto foi transformada para logaritmo na base 10. Após a transformação, os dados apresentaram distribuição normal e foram incorporados às análises estatísticas. A composição química bromatológica do material de origem foi comparada com as médias após abertura dos silos pela análise de contraste. Os dados foram submetidos à análise de variância e os valores médios das variáveis foram testados pelo teste de Tukey, utilizando-se o programa computacional SAS (versão 9.1).

\section{Resultados e Discussão}

Os dados obtidos nas avaliações da composição químico bromatológica do material de origem foram comparados com as médias após abertura dos silos (Tabela 1), apresentando diferença estatística $(\mathrm{P}<0,05)$ para as variáveis MS, FDA, CNF, NIDA, NIDN e MM. Os níveis médios encontrados foram compatíveis às observações de Pereira et al. (2008), que também utilizaram o bagaço de laranja in natura fornecida pela COROL Citrus (Rolândia, PR), apresentando teores de $24,41 \%$ de MS, $7,44 \%$ de PB, 34,46\% de FDN, 33,0\% de FDA e 3,2\% de EE.

O teor de MS (Tabela 1) do bagaço de laranja in natura $(18,73 \%)$ no presente trabalho está aquém das recomendações de McDonald, Henderson e Heron (1991) e Cheeke (1999), que citam valores entre 25 a $35 \%$, para a confecção de uma boa silagem. Os mesmos afirmam ainda que teores de MS abaixo $25 \%$ prejudicam a fermentação e favorecem o desenvolvimento de Clostridium e as perdas com efluentes. Os teores de PB (Tabela 1) do bagaço in natura não se diferenciaram antes e após 
a ensilagem, e foram inferiores aos apresentados por Ashbell e Donahaye (1984), 8,3\% de PB; e maiores que os obtidos por Megías, Martinez-Teruel e Gallego (1993), demonstrando a discrepância entre os resultados da composição do bagaço de laranja, que por muitas vezes pode ser justificada pelos diferentes métodos realizados entre as esmagadoras.

Houve aumento nos teores de FDA (Tabela 1) entre o momento de ensilagem e após abertura do silo, enquanto os teores de FDN não se diferenciaram estatisticamente mas foram numericamente superiores aos valores antes da ensilagem. Esse aumento no conteúdo de parede celular após o processo fermentativo é consolidado na literatura, uma vez que ocorre o consumo dos carboidratos solúveis pelos microrganismos, corroborando com diversos autores (EVANGELISTA et al., 2009, COAN et al., 2007). O consumo dos carboidratos solúveis pode ser demonstrado pela redução significava ocorrida nos CNF antes e pós ensilagem.

Não houve efeito do uso de diferentes aditivos sobre as perdas por gases e efluentes (Tabela 2). Esperava-se que o uso de Lactobacillus buchneri proporcionasse maior produção de gases, por ser uma bactéria heterofermentativa (OUDE ELFERINK et al., 2001) e também que as silagens inoculadas com Lactobacillus plantarum tivessem menores produções de efluentes (MCDONALD; HENDERSON; HERON, 1991). Apesar das perdas por efluentes não terem diferido $(\mathrm{P}>0,05)$, verificouse que a silagem de bagaço de laranja sem inoculantes teve produção de efluente numericamente superior, mostrando que o uso dos inoculantes pode ter auxiliado na redução destas perdas.

Tabela 2. Valores médios das perdas por gases, por efluentes, recuperação de matéria seca (RMS) e recuperação do FDN (RFDN) nos diferentes tratamentos.

\begin{tabular}{lccc}
\hline Tratamentos $^{1}$ & $\begin{array}{c}\text { Gases } \\
(\%)\end{array}$ & $\begin{array}{c}\text { Efluentes } \\
\text { Kg/ton MV }\end{array}$ & $\begin{array}{c}\text { RMS } \\
(\%)\end{array}$ \\
\hline CONT & 1,66 & 53,37 & 89,06 \\
BUCH & 1,74 & 43,94 & 95,70 \\
LAC & 1,94 & 46,55 & 89,45 \\
LACBUCH & 1,80 & 45,92 & 91,12 \\
\hline Média & 1,90 & 47,45 & 91,55 \\
CV $^{2}$ & 32,47 & 13,69 & 8,74 \\
$\mathrm{P}^{3}$ & 0,38 & 0,24 & 0,44 \\
\hline
\end{tabular}

1_CONT- silagem de bagaço de laranja, LAC - silagem de bagaço de laranja + Lactobacillus plantarum, BUCH - silagem de bagaço de laranja + Lactobacillus buchneri; LACBUCH - silagem de bagaço de laranja + Lactobacillus plantarum e buchneri ${ }^{2} \mathrm{CV}=$ coeficiente de variação; 3 = valor de p no teste de $\mathrm{F}$ da análise de variância

Fonte: Elaboração dos autores.

As elevadas perdas com efluentes, de $47,5 \mathrm{~kg} /$ ton MV (Tabela 2) em média, permitiram elevar o teor de matéria seca do bagaço de laranja $(p<0,05)$, que variou de $18,73 \%$ (antes do fechamento do silo) para $19,31 \%$ (na abertura do silo), aumentando em 0,58 pontos percentuais, o que proporcionou valores de recuperação de materia seca acima de $80 \%$.
A silagem controle, sem inoculantes, apresentou menor percentual de recuperação de matéria seca $(89,06 \%)$ que as demais, entretanto não houve diferença significativa entre os tratamentos avaliados (Tabela 2). Discordando desses dados, outros autores verificaram que o uso de Lactobacillus plantarum levou a incrementos significativos na taxa de recuperação de matéria seca das silagens de 
capim elefante e Mombaça (ZANINE et al. 2006, PENTEADO; SANTOS; CARVALHO, 2007).

Com relação às perdas por gases (Tabela 2), a média de $1,90 \%$, está em consonância com outras pesquisas realizadas com gramíneas tropicais, como observaram em capim Tanzânia perdas entre 3,1 a 4,0\% (IGARASI, 2002) e em Brachiaria brizantha cv. Marandu perdas de 3,7\% (RIBEIRO et al., 2009). É possível fazer essa comparação uma vez que esses materiais também apresentaram menos de $25 \%$ de MS antes da ensilagem.

Os teores de MS, de PB, de CNF, de MM, de EE (Tabela 1) encontrados nos diferentes tratamentos não alteraram significativamente com a inclusão dos inoculantes. Da mesma forma, Rodrigues et al. (2002) também testando diversos inoculantes microbianos, porém em silagem de sorgo, não verificaram diferenças significativas na composição química dessa silagem entre os diferentes tratamentos, e concluíram que para esta gramínea não é necessário o uso de inoculantes microbianos.

A média do teor de MS observada no presente trabalho $(19,31 \%)$ foi superior ao observado por Faria, Tosi e Silveira (1971), que avaliando também a silagem de bagaço de laranja encontraram valores médios de 12,81\% de MS. Entretanto nesse trabalho citado a polpa foi ensilada em sacos plásticos, que não permitem a saída dos efluentes e podem comprometer alguns resultados, além de subestimar o teor de MS. Em outra pesquisa com materiais de elevada umidade (capim elefante) também não verificaram efeitos quanto ao teor de matéria seca ao utilizar Lactobacillus plantarum (ZANINE et al., 2006).

$\mathrm{O}$ teor de $\mathrm{PB}$ das silagens, não se alterou em função dos tratamentos e ficou em torno de $7 \%$, semelhante às observações de Ítavo et al. (2000a) que observaram teores entre 6,8 e $7,2 \%$ para silagens de bagaço de laranja com aditivos microbianos. $\mathrm{O}$ efeito do uso de inoculantes microbianos sobre o teor de PB das silagens ainda não está bem definido, uma vez que os resultados são controversos em outros materiais ensilados com maior freqüência (sorgo e milho), ora apresentando alteração no teor de PB com a inclusão dos inoculantes (SILVA et al., 1997); ora sem apresentar diferença ao usar inoculantes (PEDROSO, FREITAS; SOUZA, 2000).

Para capins tropicais, com valores nutricionais semelhantes ao bagaço de laranja, os efeitos relatados com o uso de inoculantes têm sido de pequena magnitude (HENRIQUE; VIEIRA BOSSE, 1992). Em contrapartida, outras pesquisas mostraram efeitos positivos da associação de inoculantes microbianos com uma fonte de carboidratos solúveis (TAMADA et al., 1999), provavelmente aumentando a taxa de crescimento dos microorganismos. Perante tais dados, sugere-se que a ensilagem do bagaço de laranja associada com outras fontes de carboidratos solúveis apresentaria melhores resultados com o uso de inoculantes microbianos.

Os teores de FDN e FDA (Tabela 3) foram significativamente superiores para a silagem com Lactobacillus buchneri em relação à silagem controle, o que pode ter ocorrido devido às perdas de carboidratos solúveis durante a fermentação, aumentando proporcionalmente a concentração dos componentes da fibra na MS total (PEDROSO et al. 2005). Contrariando esses resultados Pedroso et al. (2007) demonstraram que o uso do Lactobacillus buchneri em silagem de cana de açúcar reduziu os teores de FDN e melhorou o valor nutritivo da silagem. Esses resultados demonstram que o uso do Lactobacillus buchneri em silagem de bagaço de laranja pode não ser o mais indicado para promover a melhora do valor nutritivo da silagem de bagaço de laranja. 
Tabela 3. Valores médios de $\mathrm{pH}(\mathrm{pH})$, nitrogênio amoniacal (NAMO, \%N-NH3 do N TOTAL), ácido acético (ACE,\%), ácido propiônico (PROP\%), ácido butírico (BUT\%), ácido valérico (VAL \%), ácido isovalérico (ISOVAL $\%)$, das silagens.

\begin{tabular}{lccccccr}
\hline \multicolumn{7}{c}{ Tratamentos $_{1}$} \\
\hline pH & CONT & BUCH & LAC & LACBUCH & MÉDIA & $\mathrm{P}_{2}$ & $\mathrm{CV}_{3}$ \\
NAMO & 3,31 & 3,33 & 3,45 & 3,35 & 3,35 & 0,17 & 2,71 \\
PROP & 8,64 & 9,09 & 9,46 & 7,56 & 8,69 & 0,57 & 22,65 \\
BUT & 0,300 & 0,386 & 0,206 & 0,251 & 0,285 & 0,51 & 60,27 \\
ACE & 0,058 & 0,054 & 0,080 & 0,052 & 0,061 & 0,28 & 35,59 \\
VAL & 11,964 & 11,497 & 11,069 & 11,591 & 11,530 & 0,89 & 14,06 \\
ISOVAL & 0,007 & 0,006 & 0,008 & 0,008 & 0,007 & 0,92 & 36,59 \\
\hline
\end{tabular}

Médias seguidas por letras diferentes na linha diferem entre si pelo teste de Tukey $(\mathrm{P}>0,05)$.

$1-1$ - CONT - silagem de polpa cítrica, LAC - silagem de polpa cítrica + Lactobacillus plantarum, BUCH - silagem de polpa cítrica + Lactobacillus buchneri; $L A C B U C H$ - silagem de polpa cítrica + Lactobacillus plantarum e buchneri

2 - $\mathrm{P}$ - probabilidade; 3 - CV - coeficiente de variação.

Fonte: Elaboração dos autores.

Os teores de NIDN (Tabela 3) foram inferiores para a silagem inoculada com o Lactobacillus plantarum em relação à silagem controle, e não se alterou entre os demais tratamentos. Os teores de NIDA foram estatisticamente superiores para as silagens controle e inoculadas com L. buchneri em relação à silagem com L. plantarum e L. buchneri, mostrando que essa associação de Lactobacillus traz vantagens à qualidade da silagem. Os valores elevados de NIDA são indesejáveis pois representa fração protéica indigestível, corresponde às proteínas associadas à lignina, complexos taninoproteína e produtos oriundos da reação de Maillard, altamente resistentes às enzimas microbianas e indigestíveis ao longo do trato gastrintestinal (LICITRA; HERNANDEZ; VAN SOEST, 1996).

Os teores de nitrogênio amoniacal, os valores de $\mathrm{pH}$ e os percentuais de ácidos orgânicos (Tabela 4), são alguns dos parâmetros que caracterizam a qualidade da silagem após o processo fermentativo. Os valores médios de $\mathrm{pH}$ nos mini silos no dia da abertura não se diferenciaram entre os tratamentos estudados $(p>0,05)$. Contrariando esses resultados, Penteado, Santos e Carvalho (2007), avaliando silagem de capim Mombaça verificaram redução no $\mathrm{pH}$ ao inocular Lactobacillus plantarum no material; e da mesma forma Bernardes et al. (2007) em silagem de capim Marandu, como era de se esperar. De modo geral, os aditivos utilizados deveriam reduzir as perdas de matéria seca, reduzir o $\mathrm{pH}$ e as fermentações secundárias, melhorar a estabilidade aeróbia e o valor nutritivo das silagens (HENDERSON, 1993). Entretanto seus efeitos estão condicionados ao tipo de inoculante e sua atividade biológica, à quantidade aplicada e ao tipo de forragem, em teor de matéria seca e composição química (HARRISON; BLAUWIEKEL; STOKES, 1994).

Não foram verificadas variações no teor de nitrogênio amoniacal com a adição dos diferentes inoculantes no bagaço de laranja $(\mathrm{P}>0,05)$, sendo a média observada de $8,69 \%$ de N-NH3 em relação ao nitrogênio total, ou seja, valores estes considerados como aceitáveis para classificar como silagem de boa qualidade, de acordo com Lavezzo e Andrade (1994); que citam como valores normais a variação de 0 a $12,5 \%$ N-NH3/NT.

Com relação aos ácidos orgânicos, não houve diferença significativa entre as silagens avaliadas (Tabela 4). Devido a escassez de publicações contendo os teores dos ácidos orgânicos em silagem de bagaço de laranja in natura, os dados serão comparados a espécies forrageiras ensiladas com baixos teores de matéria seca, como as gramíneas tropicais em geral. 
Os níveis de ácido propiônico, variaram de 0,25 a $0,38 \%$ e estão de acordo com os valores estabelecidos por Roth e Undersander (1995) para uma boa silagem; e estão similares às observações de Carvalho et al.(2008) e Rodrigues et al. (2002), ambos avaliando capim elefante.

Para o ácido butírico as concentrações médias na matéria seca foram de $0,061 \%$,e podem ser consideradas como baixas, demonstrando que não houve efetivamente fermentação clostrídica e indicando boa qualidade da silagem, uma vez que não foi detectada a presença de mofos e bolores no material ensilado. Resultados semelhantes foram observados em pesquisa realizada em Brachiaria decumbens, com valores entre 0,04 e $0,19 \%$ (SANTOS et al., 2011) e resultados superiores observados em capim elefante, entre 0,14 e 0,21\% (CARVALHO et al., 2008).

As concentrações de ácido acético, foram em média $11,53 \%$ da matéria seca, o que não é considerado como adequado, sendo o ideal para as silagens apresentarem níveis inferiores a $2 \%$ da matéria seca para classificá-las como de "boa qualidade", segundo Roth e Undersander (1995).

\section{Conclusão}

$\mathrm{O}$ uso dos inoculantes microbianos em silagem de bagaço de laranja não resultou em benefícios significativos relacionados às perdas durante a ensilagem ou componentes nutricionais para os animais.

\section{Agradecimentos}

À fornecedora do bagaço de laranja, Corol Cooperativa Agroindustrial Citrus (pertencente à COCAMAR CITRUS).

\section{Referências}

ASHBELL, G.; DONAHAYE, E. Losses in orange peel silage. Agricultural Wastes, Bet Dagan, v. 11, n. 1, p. 7377, 1984.
BERNARDES, T. F.; REIS, R. A.; SIQUEIRA, G. R.; AMARAL, R. C.; PIRES, A. J. V. Estabilidade aeróbia da ração total e de silagens de capim-marandu tratadas com aditivos químicos e bacterianos. Revista Brasileira Zootecnia,Viçosa, MG, v. 36, n. 4, p. 754-762, 2007.

CARVALHO, G. G. P.; GARCIA, R.; PIRES, A. J. V.; PEREIRA, O. G.; FERNANDES, F. E. P.; CARVALHO, B. M. A. Características fermentativas de silagens de capim-elefante emurchecido ou com adição de farelo de cacau. Arquivo Brasileiro de Medicina Veterinária e Zootecnia, Belo Horizonte, v. 60, n. 1, p. 234-242, 2008.

CHEEKE, P. R. Applied animal nutrition: feeds and feeding. 2. ed. New Jersey: Prentice-Hall, 1999. 525 p.

COAN, R. M.; REIS, R. A.; GARCIA, G. R.; SCHOCKEN-ITURRINO, R. P.; FERREIRA, D. S.; RESENDE,F. D.; GURGEL, F.A. Dinâmica fermentativa e microbiológica de silagens dos capins Tanzânia e Marandu acrescidas de polpa cítrica peletizada. Revista Brasileira de Zootecnia, Viçosa, MG, v. 36, n. 5, p. 15021511, 2007. Suplemento.

ERWIN, E. S.; MARCO, G. J.; EMERY, E. M. Volatile fatty acid analyses of blood and rumen fluid by gas chromatography. Journal of Dairy Science, Champaign, v. 44 , n. 9 , p. 1768-1771, 1961.

EVANGELISTA, A. R.; SIQUEIRA, G. R.; LIMA, J. A.; LOPES, J.; REZENDE, A. V. Perfil fermentativo de silagens de cana-de-açúcar com e sem inclusão de milho desintegrado com palha e sabugo. Revista Brasileira de Zootecnia, Viçosa, MG, v. 38, n. 1, p. 20-26, 2009.

FARIA, V. P.; TOSI, H.; SILVEIRA, A. C. Avaliação da polpa de laranja fresca e ensilada como alimento para bovinos. O Solo, Piracicaba, v. 63, n. 2, p. 49-55, 1971.

HALL, M. B. Challenges with nonfiber carbohydrate methods. Journal of Animal Science, Champaign, v. 81, n. 12, p. 3226-3232, 2003.

HARRISON, J. H.; BLAUWIEKEL, R.; STOKES, M. R. Fermentation and utilization of grass silage. Journal of Dairy Science, Champaign, v. 77, n. 10, p. 3209-3235, 1994.

HENDERSON, N. Silage additives. Animal Feed Science and Technology, New York, v. 45, n. 1, p. 35-56, 1993.

HENRIQUE, W.; VIEIRABOSE, M. L. Efeito de aditivos enzimo-bacterianos sobre a qualidade da silagem de cpim-elefante (Pennisetum purpureum, Schum). Revista Sociedade Brasileira de Zootecnia, Viçosa, MG, v. 21, n. 3, p. 429-437, 1992.

IGARASI, M. S. Controle de perdas na ensilagem de capim Tanzânia (Panicum maximum Jacq. cv. Tanzânia) sob os efeitos do teor de matéria seca, do tamanho de 
partícula, da estação do ano e da presença do inoculante bacteriano. 2002. Dissertação (Mestrado em Ciência Animal e Pastagens) - Escola Superior de Agricultura Luiz de Queiroz. Universidade de São Paulo, Piracicaba.

ÍTAVO, L. C. V.; SANTOS, G. T.; JOBIM, C. C.; VOLTOLINI, T. V.; FERREIRA, C. Avaliação da silagem de bagaço de laranja com diferentes aditivos por intermédio dos parâmetros de fermentação ruminal de ovinos e contribuição energética dos ácidos graxos voláteis. Revista Brasileira de Zootecnia, Viçosa, MG, v. 29, n. 5, p. 1491-1497, 2000b.

ÍTAVO, L. C. V.; SANTOS, G. T.; JOBIM, C. C.; VOLTOLINI, T. V.; FARIA, K. P.; FERREIRA, C. C. B. Composição e digestibilidade aparente da silagem de bagaço de laranja. Revista Brasileira de Zootecnia, Viçosa, MG, v. 29, n. 5, p. 1485-1490, 2000a.

JOBIM, C. C.; NUSSIO, L. G.; REIS, R. A.; SCHIMIDT, P. Avanços metodológicos na avaliação da qualidade da forragem conservada. Revista Brasileira de Zootecnia, Viçosa, MG, v. 36, p. 101-120, 2007. Suplemento Especial.

KUNG JUNIOR, L. Preparation of silage water extracts for chemical analyses. Standard operating procedure. Worrilow: Ed. Delaware: University of Delaware, Ruminant Nutrition Lab., 1996. 32 p.

KUNG JUNIOR, L.; STOKES, M. R.; LIN, C. J. Silage additives. In: BUXTON, D. R.; MUCK, R. E.; HARRISON, J. H. (Ed.). Silage science and technology. Wisconsin: American Society of Agronomy, 2003. p. 305-360.

LAVEZZO,W.; ANDRADE, J. B. Conservação de forragens: feno e silagem. In: SIMPÓSIO BRASILEIRO DE FORRAGENS E PASTAGENS, 1., 1994, Campinas. Anais... Campinas: Colégio Brasileiro de Nutrição Animal, 1994. p. 105-166.

LICITRA, G.; HERNANDEZ, T. M.; VAN SOEST, P. J. Standardization of procedures for nitrogen fractionation of ruminant feeds. Animal Feed Science Technology, New York, v. 57, n. 4, p. 347-358, 1996.

MACEDO, C. A. B.; MIZUBUTI, I. Y.; MOREIRA, F. B.; PEREIRA, E. S.; RIBEIRO, E. L. A.; ROCHA, M. A.; RAMOS, B. M. O.; MORI, R. M.; PINTO, A. P.; ALVES, T. C.; CASIMIRO, T. R. Comportamento ingestivo de ovinos recebendo dietas com diferentes níveis de bagaço de laranja em substituição à silagem de sorgo na ração. Revista Brasileira de Zootecnia, Viçosa, MG, v. 36, n. 6, p. 1910-1916, 2007.

McDONALD, P.; HENDERSON, A. R.; HERON, S. J. E. The biochemistry of silage. 2. ed. Marlow: Chalcomb Publications, 1991. $340 \mathrm{p}$.
MEGÍAS, M. D.; MARTINEZ-TERUEL, A.; GALLEGO, J. A. Chemical changes during the ensiling of orange peel. Animal Feed Science Technology, New York, v. 43, n. 3, p. 269-274, 1993.

MENEGHETTI, C. D. C.; DOMINGUES, J. L. Características nutricionais e uso de subprodutos da agroindústria na alimentação de bovinos. Revista Eletrônica Nutritime, Viçosa, v. 5, n. 2, p. 512-536, 2008.

OUDE ELFERINK, S. J. W. H.; KROONEMAN, J.; GOTTSCHAL, J. C.; SPOELSTRA, S. F.; FABER F.; DRIEHUIS, F. Anaerobic conversion of lactic acid to acetic acid and 1,2-propanediol by Lactobacillus buchneri. Applied and Environmental Microbiology, Washington, v. 67, n. 1, p. 125-132, 2001.

PEDROSO, A. F.; NUSSIO, L. G.; LOURES, D. R. S.; PAZIANI, S. F.; IGARASI, M. S.; COELHO, R. M.; HORII, J. RODRIGUES, A. A. Efeito do tratamento com aditivos químicos e inoculantes bacterianos nas perdas e na qualidade de silagens de cana-de-açúcar. Revista Brasileira de Zootecnia, Viçosa, MG, v. 36, n. 3, p. 558564, 2007.

PEDROSO, A. F.; FREITAS, A. R.; SOUZA, G. B. Efeito de inoculante bacteriano sobre a qualidade da silagem e perda de matéria seca durante a ensilagem de sorgo. Revista Brasileira de Zootecnia, Viçosa, MG, v.29, n. 1, p. 48-52, 2000.

PEDROSO, A. F.; NUSSIO, L. G.; PAZIANI, S. F.; LOURES, D. R. S.; IGARASI, M. S.; COELHO, R. M.; PACKER, I. H.; HORII, J.; GOMES, L. H. Fermentation and epiphytic microflora dynamics in sugar cane silage. Scientia Agricola, Piracicaba, v. 62, n. 5, p. 427-432, 2005.

PENTEADO, D. C. S.; SANTOS, E. M.; CARVALHO, G. G. P. Inoculação com Lactobacillus plantarum da microbiota em silagem de capim Mombaça. Archivos de Zootecnia, Córdoba, v. 56, n. 214, p. 191-202, 2007.

PEREIRA, M. S.; RIBEIRO, E. L.A.; MIZUBUTI, I. Y.; ROCHA, M. A.; KURAOKA, J. T.; NAKAGHI, E. Y. O. Consumo de nutrientes e desempenho de cordeiros em confinamento alimentados com dietas com polpa cítrica úmida prensada em substituição à silagem de milho. Revista Brasileira de Zootecnia, Viçosa, MG, v. 37, n. 1, p. 134-139, 2008.

RIBEIRO, J. L.; NUSSIO, L. G.; MOURÃO, G. B.; QUEIROZ, O. C. M.; SANTOS, M. C.; SCHMIDT, P. Efeitos de absorventes de umidade e de aditivos químicos e microbianos sobre o valor nutritivo, o perfil fermentativo e as perdas em silagens de capim-marandu. Revista Brasileira de Zootecnia, Viçosa, MG, v. 38, n. 2, p. 230-239, 2009 
RODRIGUES, P. H. M.; SENATORE, A. L.; ANDRADE, S. J. T.; RUZANTE, J. M.; LUCCI, J. M.; LIMA, F. R. Efeitos da Adição de Inoculantes Microbianos sobre a Composição Bromatológica e Perfil Fermentativo da Silagem de Sorgo Produzida em Silos Experimentais. Revista Brasileira de Zootecnia, Viçosa, MG, v. 31, n. 6, p. 2373-2379, 2002.

ROTH, G.; UNDERSANDER, D. Silage additives. In: . Corn silage production management and feeding. Madison: Madison American Society of Agronomy, 1995. p. 27-29.

SANTOS, E. M.; PEREIRA, O. G.; FERREIRA, C. L. L. F.; OLIVEIRA, J. S.; SILVA, T. C.; ROSA, L. O. Microbial populations, fermentative profile and chemical composition of signalgrass silages at different regrowth ages. Revista Brasileira de Zootecnia, Viçosa, MG, v. 40, n. 4, p. 747-755, 2011.

SILVA, A. W. L.; MACEDO, A. F.; MIGUELLUTI, D. J.; HOESCHL NETO, W. Efeito do uso de inoculante bacteriano e de diferentes proporções de grãos na massa sobre a composição bromatológica da silagem de milho. In: REUNIÃO ANUAL DA SOCIEDADE BRASILEIRA DE ZOOTECNIA, 34., 1997, Juiz de Fora. Anais... Juiz de Fora: SBZ, 1997. p. 170-172.
SILVA, D. J.; QUEIROZ, C. Análise de alimentos: métodos químicos e biológicos. Viçosa, MG: Universidade Federal de Viçosa, 2006.

SNIFFEN, C. J.; O'CONNOR, D. J.; VAN SOEST, P. J.; RUSSEL, J. B. A net carbohydrate and protein system for evaluating cattle diets: carbohydrate and protein availability. Journal of Animal Science, Champaign, v. 70, n. 12, p. 3562-3577, 1992.

TAMADA, J.; YOKOTA, H.; OHSHIMA, M.; TAMAKI, $M$. Effect of additives, storage temperature and regional difference of ensiling on the fermentation quality of napier grass (Pennisetum purpureum, Schum) silage. Asian Australian Journal of Animal Science, Geneva, v. 12, n. 1, p. 28-35, 1999.

ZANINE, A. M.; SANTOS, E. M.; FERREIRA, D. J.; OLIVEIRA, J. S.; ALMEIDA, J. C. C.; PEREIRA, O. G. Avaliação da silagem de capim-elefante com adição de farelo de trigo. Archives de Zootecnia, v. 55, n. 209, p. 75-84, 2006. 